\title{
Studies on the Polymerization of Acrolein Oxime. IV. The Polymerization by Butyllithium
}

\author{
Seizo Masuda, Masami Tanaka, and Tadatoshi Ota \\ Department of Applied Chemistry, Faculty of Engineering, \\ Tokushima University, Tokushima 770, Japan.
}

(Received September 16, 1977)

\begin{abstract}
The rate of polymerization of acrolein oxime initiated by $n$-butyllithium has been studied at temperatures ranging from 20 to $50^{\circ} \mathrm{C}$. The characteristic time-conversion curves obtained depended on the type of solvent used: The acceleration of reaction was initially observed in the bulk polymerization. The use of dichloroethane as a solvent gave a linear relationship of time-course, whereas polymerization in tetrahydrofuran was violent at the initial stage and afterward proceeded at a constant rate. The initial rate was proportional to the square root of the concentration of butyllithium for the bulk polymerization, whereas for the solution polymerization, the rate was proportional to the first power of the concentrations of both the $n$-butyllithium and acrolein oxime. A consistent explanation for this polymerization behavior is as follows: (1) The polymerization involves no termination process and a stable polymer is produced only by a chain transfer reaction with acrolein oxime. (2) The polymerization proceeds through an initiation step by a reaction of $n$-butyllithium with acrolein oxime, each of which has different aggregation factor depending on the kind of solvent used.
\end{abstract}

KEY WORDS Acrolein Oxime / Anionic Polymerization/ Kinetics / Solvent Effect / Structure of Polymer / Polymer Reaction /

The detailed kinetics for the thermal polymerization of acrolein oxime (AOM) was reported in a preceding paper. ${ }^{1}$ The polymerization is initiated by the anion, which is produced by an ionic dissociation of the molecular aggregates of AOM, and follows an anionic mechanism. ${ }^{2}$ In order to elucidate the mechanism of the polymerization initiated by butyllithium (BuLi) and to compare it with that of the thermal polymerization, the polymerization was studied without solvent and in the presence of 1,2-dichloroethane (DCE) or tetrahydrofuran (THF).

\section{EXPERIMENTAL}

\section{Materials}

AOM was prepared by the oximation of acrolein described previously. ${ }^{3}$ bp $44^{\circ} \mathrm{C}(14 \mathrm{~mm})$. All solvents used were purified by the usual methods.

\section{Polymerization Procedure}

The polymerization was carried out at a given temperature under agitation in a glass tube pro- vided with a rubber plug through which a solution of BuLi was injected. The reactor tubes were opened after a designated time and the contents were brought together, with the addition of a large amount of ether so that the polymers could precipitate. The resulting polymers were dried throughly under reduced pressure and weighed.

Characterization of Poly(acrolein oxime) (PAOM)

The molecular weight of PAOM was determined in a dimethylformamide solution at $70^{\circ} \mathrm{C}$ using a vapor-pressure osmometer (Hitachi Perkin-Elmer, model 115). The oxime group in PAOM was reduced to the primary amine with hydrogen in the presence of a Raney nickel catalyst, ${ }^{4}$ and the amount of the resulting amine was determined by the Van Slyke method. ${ }^{5}$ The content of carboncarbon double bond was calculated by determining the iodine value. ${ }^{6}$

The NMR spectra were obtained with a JEOL PS-100 spectrometer $(100 \mathrm{MHz})$ at $24^{\circ} \mathrm{C}$, using deuterated dimethylsulfoxide (DMSO- $d_{6}$ ) as the 
solvent and tetramethylsilane (TMS) as the internal standard. The concentration was approximately $10 \%(\mathrm{w} / \mathrm{v})$.

\section{Equimolar Reaction of AOM and BuLi}

To $25 \mathrm{~m} l$ of hexane containing $0.026 \mathrm{~mol}$ of BuLi was added $1.73 \mathrm{ml}(0.024 \mathrm{~mol})$ of AOM. Stirred for $2 \mathrm{hr}$ at $0^{\circ} \mathrm{C}$, the solution was shaken with water. The aqueous layer was neutralized with hydrochloric acid and then extracted with ether. The ether and organic layer were combined and evaporated to yield $1.8 \mathrm{~g}$ of the concentrate. It was distilled to give about $1.15 \mathrm{~g}$ of $\mathrm{AOM}$ and a viscous liquid residue which became solid below $0^{\circ} \mathrm{C}$.

\section{Hydrolysis of PAOM}

A solution of $1 \mathrm{~g}$ of PAOM in $30 \mathrm{ml}$ of $5-\%$ sulfuric acid was heated at $60^{\circ} \mathrm{C}$ for $24 \mathrm{hr}$. The cooled solution was adjusted to $\mathrm{pH} 7$ with barium hydroxide solution. After removal of the barium sulfate by centrifugation, the supernatant was evaporated to dryness. The yield was $760 \mathrm{mg}$. The molecular weight of the hydrolyzed product was determined in an aqueous solution at $40^{\circ} \mathrm{C}$ by a vapor-pressure osmometer.

\section{RESULTS AND DISCUSSION}

Dependence of the Polymerization Rate on the Catalyst Concentration

Figures $1-3$ show the time-conversion curves for the $A O M$ polymerization at $30^{\circ} \mathrm{C}$ at different catalyst concentrations. In the bulk polymerization, the reaction was initially accelerated and afterward proceeded at a constant rate up to high conversions $(<70 \%)$. The use of DCE as the solvent gave a linear relationship between the time and conversion from the beginning of the reaction to $<65 \%$, while the polymerization in THF was initially violent but afterward the rate remained constant up to high conversions. The lithium hydroxide-catalyzed polymerization was carried out for comparison, and the plot of time vs. conversion was linear (Figure 4). In order to obtain value for the rate of polymerization in the kinetic study, the curve obtained should be extrapolated to zero time. A plot of the polymerization rate $v s$. catalyst concentration is shown in Figure 5, from which the reaction order with respect to the

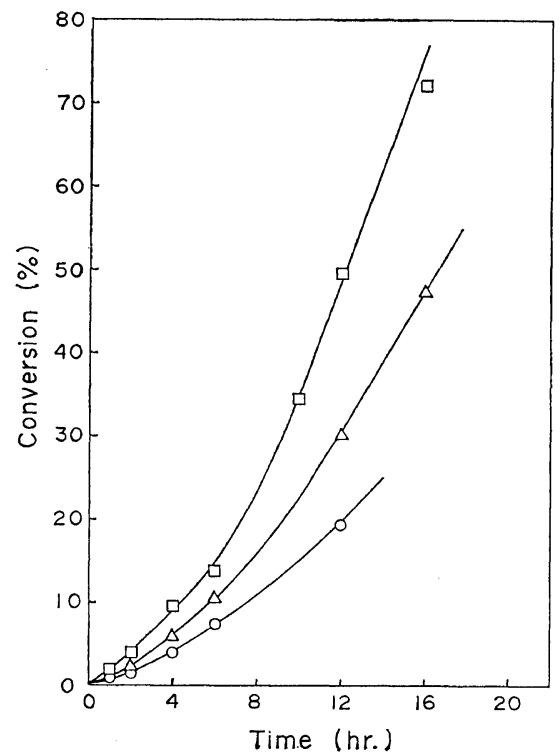

Figure 1. Time--conversion curves for bulk polymerization of $\mathrm{AOM}$ at $30^{\circ} \mathrm{C}: \mathrm{O},[\mathrm{BuLi}]=1.13 \times 10^{-2}$; $\triangle, 2.26 \times 10^{-2} ; \square, 4.52 \times 10^{-2} \mathrm{~mol} / l$.

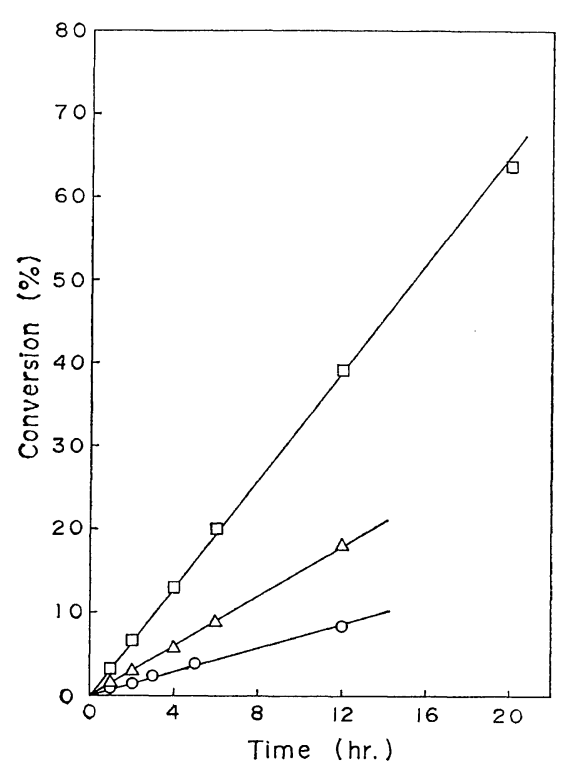

Figure 2. Time-conversion curves for AOM polymerization in DCE at $30^{\circ} \mathrm{C}:[\mathrm{AOM}]=6.86 \mathrm{~mol} / l ; O$, $[\mathrm{BuLi}]=1.13 \times 10^{-2} ; \triangle, 2.26 \times 10^{-2} ; \square, 4.52 \times 10^{-2}$ $\mathrm{mol} / l$.

concentration of catalyst can be estimated (Table I). 
AOM Polymerization by Butyllithium

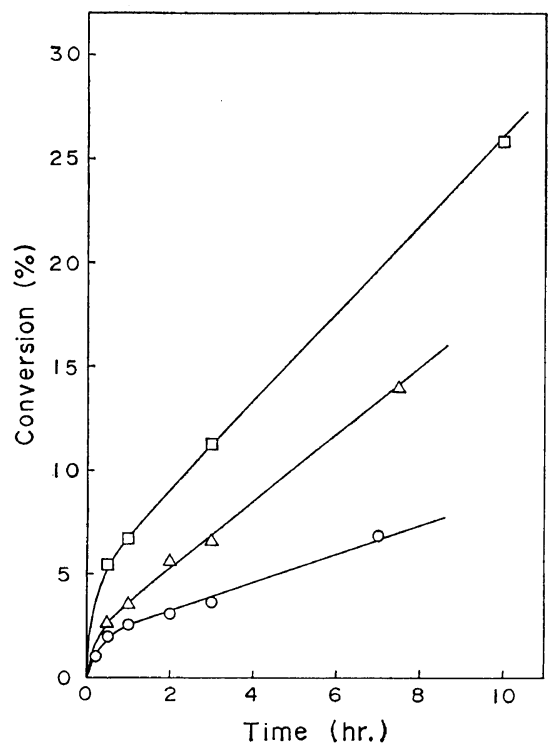

Figure 3. Time-conversion curves for AOM polymerization in $\mathrm{THF}$ at $30^{\circ} \mathrm{C}:[\mathrm{AOM}]=6.86 \mathrm{~mol} / l, \mathrm{O}$, $\left[\right.$ BuLi] $=1.13 \times 10^{-2} ; \triangle, 2.26 \times 10^{-2} ; \square, 4.52 \times 10^{-2}$ $\mathrm{mol} / l$.

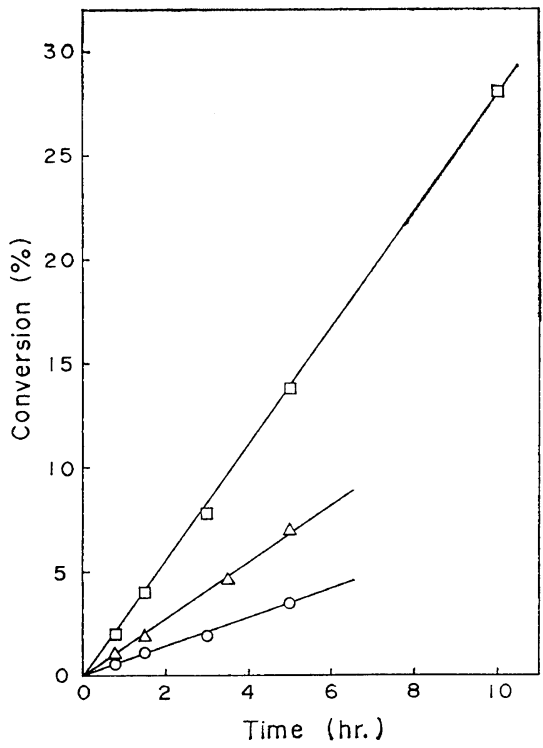

Figure 4. Time-conversion curves for bulk polymerization of $A O M$ at $30^{\circ} \mathrm{C}: \mathrm{O},[\mathrm{LiOH}]=0.63 \times 10^{-2}$; $\Delta, 1.25 \times 10^{-2} ; \square, 2.50 \times 10^{-2} \mathrm{~mol} / l$.

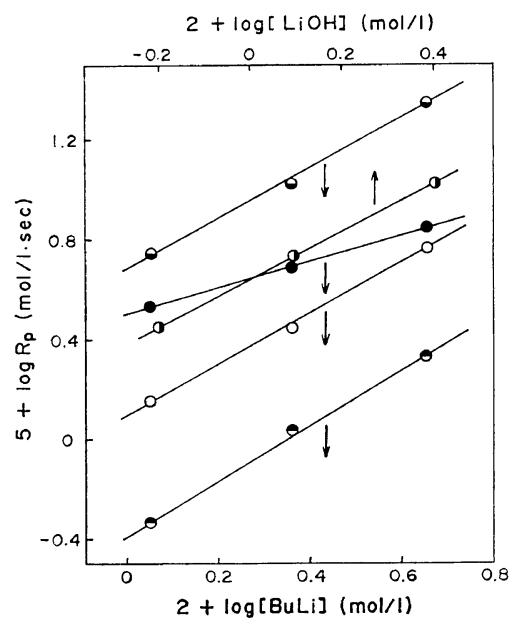

Figure 5. Dependence of polymerization rate on catalyst concentration.

Solvent: $\bullet$, none; O, DCE; $\bullet$, THF (in initial stage);

$\ominus$, THF (in stationary stage); $\mathbf{\oplus}$, none.

Table I. Reaction order for AOM polymerization

\begin{tabular}{lccc}
\hline Solvent & \multicolumn{2}{c}{ Reaction order } & Activation \\
\cline { 2 - 3 } & $\begin{array}{c}\text { With } \\
\text { respect } \\
\text { to BuLi } \\
\text { concn }\end{array}$ & $\begin{array}{c}\text { With } \\
\text { respect } \\
\text { to AOM } \\
\text { concn }\end{array}$ & kcal/mol \\
\hline None & 0.54 & & 13.5 \\
None & $1.0^{\mathrm{b}}$ & & \\
DCE & 1.0 & 1.0 & 17.2 \\
THF & 1.0 & 1.0 & 12.8 \\
THF $^{\mathrm{a}}$ & 1.0 & 1.0 & 13.1 \\
\hline
\end{tabular}

${ }^{a}$ Measured at a stationary stage of polymerization.

b With respect to $\mathrm{LiOH}$ concentration.

Dependence of the Polymerization Rate on AOM Concentration

The polymerization of $\mathrm{AOM}$ with $[\mathrm{BuLi}]=$ $1.13 \times 10^{-2} \mathrm{~mol} / l$ was carried out at $30^{\circ} \mathrm{C}$ in two solvents and the dependence of the polymerization rate on the AOM concentration was evaluated over the concentration range from 3.43 to 10.29 $\mathrm{mol} / l$. The shape of the time-conversion curves obtained are similar to those shown in Figures 2 and 3 when the same solvents are used. Figure 6 indicates the relationship between the polymerization rate and $\mathrm{AOM}$ concentration. The reaction orders are summarized in Table $\mathrm{I}$. 


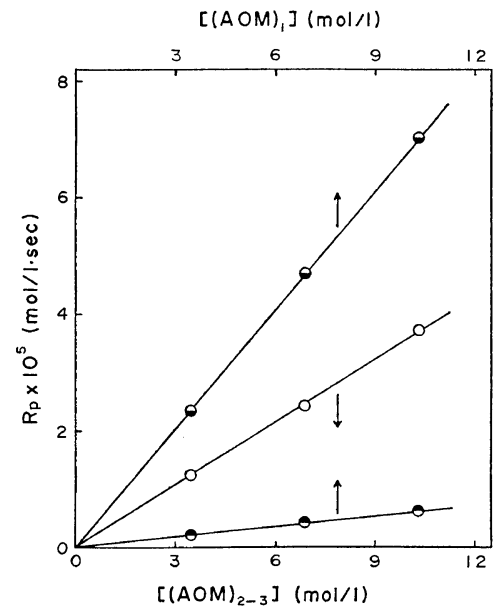

Figure 6. Dependence of polymerization rate on AOM concentration.

Solvent: $\mathrm{O}, \mathrm{DCE}$; $\ominus$, THF (in initial stage); $\ominus$, THF (in stationary stage).

\section{Temperature-Dependence of Polymerization Rate}

Polymerization with $[\mathrm{BuLi}]=1.13 \times 10^{-2} \mathrm{~mol} / l$ was carried out at in a temperature range from 20 to $50^{\circ} \mathrm{C}$. From Arrhenius plots shown in Figure 7 , the activation energies were calculated to be 13.5 (without solvent), 17.2 (in DCE), 12.8 (in THF, at initial stage) and $13.1 \mathrm{kcal} / \mathrm{mol}$ (in THF, in stationary stage), respectively. The higher activation energy for the polymerization in DCE is due to the predominant initiation by lithium acro-

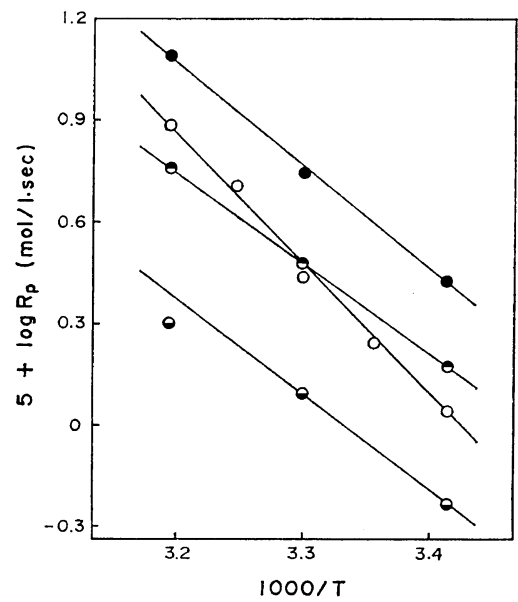

Figure 7. Dependence of polymerization rate on temperature.

Solvent: $\bullet$, none; O, DCE; $\Theta$, THF (in initial stage); $\ominus$, THF (in stationary stage). lein oxime. Thus, the activation energy for initiation by lithium acrolein oxime is greater than that by butyl anion. This finding is supported by the fact that the value of activation energy for the thermal polymerization is $21.5 \mathrm{kcal} / \mathrm{mol}{ }^{1}$

Kinetics of the Bulk Polymerization of AOM

AOM molecules in liquid can associate with each other to form cyclic aggregates, mainly existing as dimer and trimer, ${ }^{1,2}$ by hydrogen bonds of two types: $\mathrm{O} \cdots \mathrm{H} \cdots \mathrm{N}$ and $\mathrm{O} \cdots \mathrm{H} \cdots \mathrm{O}{ }^{2}$ BuLi (ca. $10^{-2} \mathrm{~mol} / \mathrm{l}$ ) in AOM media seems to be in the form of the dimer because of the square-root dependence of the polymerization rate of $\mathrm{BuLi}$ concentration. Thus, BuLi may be in an aggregated form in the solution of AOM, which has strong associating ability, and the aggregation behavior of BuLi in AOM differs from that in a DCE or THF solution. Therefore, reaction scheme for the bulk polymerization can be written as follows.

Dissociation equilibrium of BuLi:

$$
(\mathrm{BuLi})_{2} \stackrel{K}{\rightleftarrows} 2 \mathrm{Bu} \ominus \ldots \mathrm{Li} \oplus
$$

Initiation by butyl anion:

$$
\begin{gathered}
\mathrm{Bu} \ominus \cdots \mathrm{Li} \oplus+(\mathrm{AOM})_{2-3} \\
\stackrel{k_{\mathrm{i}}}{\longrightarrow} \mathrm{Bu}-\mathrm{CH}_{2}-\stackrel{\ominus}{\mathrm{C}} \mathrm{H} \cdots \mathrm{Li} \oplus+(\mathrm{AOM})_{1-2} \\
\stackrel{\mathrm{C}}{\mathrm{H}}=\mathrm{N}-\mathrm{OH} \\
\left(\mathrm{P}_{1} \ominus \ldots \mathrm{Li} \oplus\right)
\end{gathered}
$$

Initiation by lithium acrolein oxime $\left(\mathrm{AOM}^{\ominus} \ldots\right.$ $\left.\mathrm{Li}^{\oplus}\right)$ :

$$
\begin{aligned}
& \mathrm{Bu} \ominus \ldots \mathrm{Li} \oplus+(\mathrm{AOM})_{2-3} \\
& \stackrel{k_{3}}{\longrightarrow} \mathrm{CH}_{2}=\mathrm{CH}-\mathrm{CH}=\mathrm{N}-\mathrm{O} \ominus \ldots \mathrm{Li} \oplus \\
& (\mathrm{AOM} \ominus \ldots \mathrm{Li} \oplus) \\
& +(\mathrm{AOM})_{1-2}+\mathrm{C}_{4} \mathrm{H}_{10} \\
& \mathrm{AOM} \ominus \ldots \mathrm{Li} \oplus+(\mathrm{AOM})_{2-3} \\
& \begin{array}{r}
\stackrel{k_{\mathrm{i}}{ }^{\prime}}{\rightarrow} \mathrm{AOM}-\mathrm{CH}_{2}-\stackrel{\ominus}{\mathrm{C}} \mathrm{H} \cdots \mathrm{Li} \oplus+(\mathrm{AOM})_{1-2} \\
\stackrel{\mathrm{CH}}{\mathrm{H}}=\mathrm{N}-\mathrm{OH}
\end{array} \\
& \left(\mathrm{P}_{1} \ominus \ldots \mathrm{Li} \oplus\right)
\end{aligned}
$$

Propagation:

$$
\begin{aligned}
\mathrm{P}_{n} \ominus & \cdots \mathrm{Li} \oplus+(\mathrm{AOM})_{2-3} \\
& \stackrel{k_{\mathrm{p}}}{\longrightarrow} \mathrm{P}_{n+1}^{\ominus} \cdots \mathrm{Li} \oplus+(\mathrm{AOM})_{1-2}
\end{aligned}
$$

The yield of polymer was directly proportional to the time up to high conversions in the bulk polymerization as well as in solution polymerizations 
which will be described later. Furthermore, the molecular weight of the polymer obtained was relatively low $(c a .1000)$. These findings indicate that the polymerization of $A O M$ involves no termination process, and that the stable polymer is produced only by a chain-transfer reaction with AOM; it is confirmed by NMR spectroscopy that the relative area obtained by integration of the peaks due to the end group, $\mathrm{CH}_{2}=\mathrm{CH}-\mathrm{CH}=\mathrm{N}-$, of the polymer is independent of conversions. Accordingly,

Chain transfer to AOM:

$$
\begin{aligned}
\mathbf{P}_{n} \ominus & \ldots \mathrm{Li} \oplus+(\mathrm{AOM})_{2-3} \\
& \stackrel{k_{\text {trm }}}{\rightarrow} \mathbf{P}_{n}-\mathrm{H}+\mathrm{AOM} \ominus \cdots \mathrm{Li} \oplus+(\mathrm{AOM})_{1-2}
\end{aligned}
$$

Chain transfer to PAOM:

$$
\begin{gathered}
\mathrm{P}_{n} \ominus \ldots \mathrm{Li} \oplus+\mathrm{PAOM} \\
\stackrel{k_{\text {trp }}}{\rightarrow} \mathrm{P}_{n}-\mathrm{H}+\sim \mathrm{CH}_{2}-\underset{\mid}{\mathrm{CH}} \sim \\
\quad \mathrm{CH}=\mathrm{N}-\mathrm{O} \ominus \ldots \mathrm{Li} \oplus \\
(\mathrm{PAOM} \ominus \ldots \mathrm{Li} \oplus)
\end{gathered}
$$

where $(\mathrm{BuLi})_{2}$ and $(\mathrm{AOM})_{2-3}$ denote molecular aggregates with an aggregation factor of 2 and 2 to 3 , respectively. $k_{1}, k_{3}, k_{1}{ }^{\prime}, k_{\mathrm{p}}, k_{\mathrm{trm}}$, and $k_{\mathrm{trp}}$ are the rate constants for the corresponding reactions, respectively, and $K$ is the equilibrium constant.

If the value of equilibrium constant $K$ is relatively small, the concentration of monomeric $\mathrm{BuLi}$ is

$$
[\mathrm{Bu} \ominus \cdots \mathrm{Li} \oplus]=K^{1 / 2}\left[(\mathrm{BuLi})_{2}\right]^{1 / 2}
$$

The NMR peak of PAOM obtained in initial stage at $\delta=1.05 \mathrm{ppm}$ assigned to methyl protons suggests that the polymerization involves initiation by a butyl anion (Figure 8). However, in the equimolar reaction of $\mathrm{AOM}$ and $\mathrm{BuLi}$ in hexane at $0^{\circ} \mathrm{C}$, the reaction according to eq 3 was also found to take place, according to the analytical results of the products. When BuLi was added to $\mathrm{AOM}$ at $0^{\circ} \mathrm{C}$, the evolution of butane was detected by gas chromatography. ${ }^{3}$ These findings imply the existence of initiation by lithium acrolein oxime. Therefore, the initiation may involve two reactions.

When the polymerization is initiated by butyl anion, the rate of initiation $\left(R_{1}\right)$ is

$$
\begin{aligned}
R_{1} & =k_{1}[\mathrm{Bu} \ominus \ldots \mathrm{Li} \oplus]\left[(\mathrm{AOM})_{2-3}\right] \\
& =k_{1} K^{1 / 2}\left[(\mathrm{BuLi})_{2}\right]^{1 / 2}\left[(\mathrm{AOM})_{2-3}\right]
\end{aligned}
$$

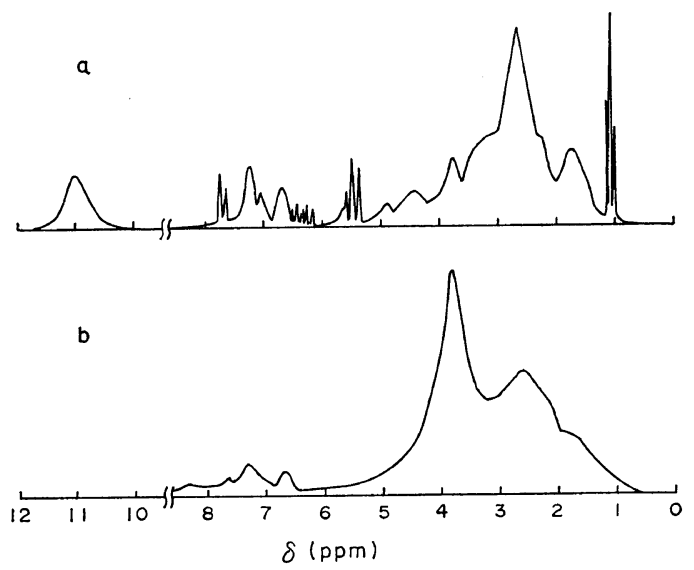

Figure 8. NMR spectra: (a) PAOM; (b) hydrolyzed PAOM.

Since there is no termination process, the initial rate of the polymerization may be proportional to the square root of $\mathrm{BuLi}$ concentration when the polymerization is initiated by butyl anion. Since $\mathrm{AOM}^{\ominus} \ldots \mathrm{Li}^{\oplus}$ resulted from the chain-transfer reaction (eq 6) can reinitiate the polymerization, the reaction is accelerated until all $\mathrm{BuLi}$ is consumed and afterward it proceeds at the constant rate.

When the polymerization is initiated by lithium acrolein oxime, the rate of initiation $\left(R_{1}{ }^{\prime}\right)$ is

$$
R_{\mathbf{1}}{ }^{\prime}=k_{1}[\mathrm{AOM} \ominus \ldots \mathrm{Li} \oplus]\left[(\mathrm{AOM})_{2-3}\right]
$$

There being no termination process, the rate $\left(R_{\mathrm{p}}\right)$ may be directly proportional to $\mathrm{AOM}^{\ominus} \ldots \mathrm{Li}^{\oplus}$ concentration in the initial stage of the polymerization. The rate equation for the formation of $\mathrm{AOM}^{\ominus} \ldots \mathrm{Li}^{\oplus}$ is

$$
\begin{aligned}
R_{3} & =k_{3}[\mathrm{Bu} \ominus \cdots \mathrm{Li} \oplus]\left[(\mathrm{AOM})_{2-3}\right] \\
& =k_{3} K^{1 / 2}\left[(\mathrm{BuLi})_{2}\right]^{1 / 2}\left[(\mathrm{AOM})_{2-3}\right]
\end{aligned}
$$

This equation also indicates the square-root dependence of the initial rate of the polymerization on BuLi concentrations. In this case too, the polymerization may be accelerated until all the BuLi is consumed and afterward proceed at a constant rate.

\section{Kinetics of the Polymerization in DCE Solution}

A DCE solution of BuLi was allowed to stand at $30^{\circ} \mathrm{C}$ for $30 \mathrm{~min}$, and was shaken with distilled water. Silver nitrate was added to the separated aqueous layer to precipitate silver chloride. In the 
case of the AOM-DCE mixture containing BuLi, similar treatment does not result in the formation of silver chloride. This finding indicates that $\mathrm{BuLi}$ reacts faster with $\mathrm{AOM}$ and so the reaction of $\mathrm{BuLi}$ and DCE can be considered negligible in the presence of AOM. The results of qualitative analysis (Beilstein's test and Lassaigne's test) of chloride in PAOM indicate that no reaction of the growing chain and DCE takes place.

When the polymerization of AOM carried out in a DCE solution in the presence of $\mathrm{BuLi}$, a plot of time against conversion gives a straight line up to high conversions $(<70 \%)$. The rate of the polymerization is proportional to the first power of the concentration of BuLi and AOM. The rate of polymerization by lithium hydroxide ( $\mathrm{LiOH}$ ) (added as aqueous solution) varies also in direct proportion to the catalyst concentration (Figure 5). A rapid reaction of $\mathrm{LiOH}$ with aggregated AOM may be shown as

$$
\begin{aligned}
& \mathrm{LiOH}+(\mathrm{AOM})_{2-3} \\
& \stackrel{k_{12}}{\longrightarrow} \mathrm{AOM} \ominus \cdots \mathrm{Li} \oplus+\mathrm{H}_{2} \mathrm{O}+(\mathrm{AOM})_{1-2}
\end{aligned}
$$

Though the system contains a small amount of water, the relationship between the time and conversion is linear up to high conversions. Thus, it is apparent that water does not serve as an inhibitor but as a chain-transfer agent.

$$
\mathrm{P}_{n} \ominus \ldots \mathrm{Li} \oplus+\mathrm{H}_{2} \mathrm{O} \stackrel{k_{\text {trw }}}{\rightarrow} \mathrm{P}_{n}-\mathrm{H}+\mathrm{LiOH}
$$

The polymerization by BuLi may show similar behavior to that by $\mathrm{LiOH}$. It seems reasonable that AOM in DCE is in the aggregated form. ${ }^{1}$ To explain this polymerization behavior, it may be assumed that the reaction of BuLi and AOM in DCE solution is very rapid, and that initiation by lithium acrolein oxime is predominant rather than that by butyl anion. Evidence for this assumption is that there is no peak due to methyl protons in the NMR spectrum of the polymer obtained. The assumption of $k_{3} \gg k_{1}{ }^{\prime}$ gives

$$
[\mathrm{AOM} \ominus \cdots \mathrm{Li} \oplus]=[\mathrm{BuLi}]
$$

Introducing the steady-state approximation with respect to the concentration of a growing polymer anion, we obtain

$$
\begin{aligned}
k_{\mathrm{i}}{ }^{\prime} & {[\mathrm{AOM} \ominus \cdots \mathrm{Li} \oplus]\left[(\mathrm{AOM})_{2-3}\right] } \\
& =k_{1}{ }^{\prime}[\mathrm{BuLi}]\left[(\mathrm{AOM})_{2-3}\right] \\
& =k_{\mathrm{trm}}\left[\mathrm{P}_{n} \ominus \cdots \mathrm{Li} \oplus\right]\left[(\mathrm{AOM})_{2-3}\right]
\end{aligned}
$$

Accordingly,

$$
\left[\mathbf{P}_{n} \ominus \ldots \mathrm{Li} \oplus\right]=\frac{k_{\mathrm{i}}^{\prime}}{k_{\mathrm{trm}}}[\mathrm{BuLi}]
$$

The overall rate $\left(R_{\mathrm{pD}}\right)$ may be represented as follows because the molecular weight of PAOM obtained is very low.

$$
\begin{aligned}
R_{\mathrm{pD}}= & R_{\mathrm{i}}{ }^{\prime}+R_{\mathrm{p}}+R_{\mathrm{trm}} \\
= & k^{\prime}{ }_{1}[\mathrm{BuLi}]\left[(\mathrm{AOM})_{2-3}\right]+k_{\mathrm{p}}\left[\mathrm{P}_{n} \ominus \cdots \mathrm{Li} \oplus\right]\left[(\mathrm{AOM})_{2-3}\right] \\
& +k_{\mathrm{trm}}\left[\mathrm{P}_{n} \ominus \cdots \mathrm{Li} \oplus\right]\left[(\mathrm{AOM})_{2-3}\right] \\
= & k_{\mathrm{i}}{ }^{\prime}[\mathrm{BuLi}]\left[(\mathrm{AOM})_{2-3}\right]\left\{\left(\mathrm{k}_{\mathrm{p}} / k_{\mathrm{trm}}\right)+2\right\}
\end{aligned}
$$

Equation 17 best demonstrates the observed results.

Kinetics of AOM Polymerization in THF Solution

AOM in THF is in the monomeric form, ${ }^{2}$ and the reaction of BuLi with AOM in THF solution may be very rapid. It is anticipated from Figure 3 that the initiation by butyl anion cannot be negligible. Accordingly, the elementary processes of polymerization are represented as follows.

Initiation by butyl anion:

$$
\mathrm{BuLi}+(\mathrm{AOM})_{1} \underset{\text { (rapid) }}{\stackrel{k_{\mathrm{i}}^{\prime \prime}}{\longrightarrow}} \mathrm{P}_{1} \ominus \ldots \mathrm{Li} \oplus
$$

Initiation by lithium acrolein oxime:

$$
\begin{gathered}
\mathrm{BuLi}+(\mathrm{AOM})_{1} \frac{k_{19}}{(\text { rapid) }} \mathrm{AOM} \ominus \ldots \mathrm{Li} \oplus \\
\mathrm{AOM} \ominus \ldots \mathrm{Li} \oplus+(\mathrm{AOM})_{1} \stackrel{k_{\mathrm{i}}^{\prime \prime \prime}}{\rightarrow} \mathrm{P}_{1} \ominus \ldots \mathrm{Li} \oplus
\end{gathered}
$$

Propagation:

$$
\mathrm{P}_{n} \ominus \cdots \mathrm{Li} \oplus+(\mathrm{AOM})_{1} \stackrel{k_{\mathrm{p}}^{\prime}}{\rightarrow} \mathrm{P}_{n+1}^{\ominus} \cdots \mathrm{Li} \oplus
$$

Chain transfer to AOM:

$\mathrm{P}_{n} \ominus \ldots \mathrm{Li} \oplus+(\mathrm{AOM})_{1} \stackrel{k_{\mathrm{trm}}}{\rightarrow} \mathrm{P}_{n}-\mathrm{H}+\mathrm{AOM} \ominus \ldots \mathrm{Li} \oplus$

Chain transfer to PAOM:

$\mathrm{P}_{n} \ominus \cdots \mathrm{Li}^{\oplus}+\mathrm{PAOM} \stackrel{k_{\mathrm{trp}}}{\rightarrow} \mathrm{P}_{n}-\mathrm{H}+\mathrm{PAOM} \ominus \ldots \mathrm{Li} \oplus$

Reinitiation:

$$
\begin{gathered}
\mathrm{AOM} \ominus(\text { or } \mathrm{PAOM} \ominus) \cdots \mathrm{Li} \oplus+(\mathrm{AOM})_{1} \\
\stackrel{k_{\mathrm{i}}^{\prime \prime \prime}}{\rightarrow} \mathrm{P}_{1} \ominus\left(\text { or } \mathrm{P}_{n+1}^{\ominus}\right) \cdots \mathrm{Li} \oplus
\end{gathered}
$$

If the polymerization is initiated by the butyl anion, at the beginning of the initial stage

$$
\left[\mathrm{P}_{n} \ominus \cdots \mathrm{Li} \oplus\right]=[\mathrm{BuLi}]
$$

Accordingly, the initial rate $\left(R_{\mathrm{p} q}^{\prime}\right)$ is

$$
R_{\mathrm{pT}}^{\prime}=k_{p}{ }^{\prime}\left[\mathrm{P}_{n} \ominus \cdots \mathrm{Li} \oplus\right]\left[(\mathrm{AOM})_{1}\right]=k_{p}{ }^{\prime}[\mathrm{BuLi}]\left[(\mathrm{AOM})_{1}\right]
$$


The results of the polymerization in THF are in close agreement with the above equation. On the other hand, the rate of polymerization gradually decreases with time because of $k_{1}{ }^{\prime \prime}<k_{\mathrm{p}}$, and in the stationary stage of the polymerization, the rate becomes constant. This is because the steadystate approximation with respect to the concentration of lithium acrolein oxime becomes valid with time.

If the polymerization is initiated by lithium acrolein oxime,

$$
[\mathrm{AOM} \ominus \cdots \mathrm{Li} \oplus]=[\mathrm{BuLi}]
$$

Introducing the steady-state approximation with respect to the concentration of lithium acrolein oxime, we obtain

$$
\begin{aligned}
k_{\mathrm{i}}{ }^{\prime \prime \prime} & {[\mathrm{AOM} \ominus \ldots \mathrm{Li} \oplus]\left[(\mathrm{AOM})_{1}\right] } \\
& =k_{\mathrm{i}}{ }^{\prime \prime}[\mathrm{BuLi}]\left[(\mathrm{AOM})_{1}\right] \\
& =k_{\mathrm{trm}}\left[\mathrm{P}_{n} \ominus \ldots \mathrm{Li} \oplus\right]\left[(\mathrm{AOM})_{1}\right]
\end{aligned}
$$

Accordingly,

$$
\left[\mathrm{P}_{n} \ominus \ldots \mathrm{Li} \oplus\right]=\frac{k_{\mathrm{i}}^{\prime \prime \prime}}{k_{\mathrm{trm}}}[\mathrm{BuLi}]
$$

Because the molecular weight of PAOM obtained is very low, the overall rate $\left(R_{\mathrm{pT}}^{\prime}\right)$ is represented as follows.

$$
\begin{aligned}
R_{\mathrm{pr}}^{\prime}= & R_{1}^{\prime \prime \prime}+R_{\mathrm{p}}{ }^{\prime}+R_{\text {trm }} \\
= & k_{\mathrm{i}}{ }^{\prime \prime \prime}[\mathrm{BuLi}]\left[(\mathrm{AOM})_{1}\right] \\
& +k_{\mathrm{p}}{ }^{\prime}\left[\mathrm{P}_{n} \ominus \cdots \mathrm{Li} \oplus\right]\left[(\mathrm{AOM})_{1}\right] \\
& +k_{\mathrm{trm}}\left[\mathrm{P}_{n} \ominus \cdots \mathrm{Li} \oplus\right]\left[(\mathrm{AOM})_{1}\right] \\
= & k_{\mathrm{i}}{ }^{\prime \prime}[\mathrm{BuLi}]\left[(\mathrm{AOM})_{1}\right]\left\{\left(k_{\mathrm{p}}{ }^{\prime} / k_{\mathrm{trm}}\right)+2\right\}
\end{aligned}
$$

In the case where the polymerization is initiated by lithium acrolein oxime, the polymerization proceeds steadily, and the rate is proportional to the first power of the BuLi concentration as is similar to the case described for polymerization in a DCE solution. Consequently, the polymerization in THF appears to involve two initiation reactions (eq 18 and 20).

\section{Chemical Structure of PAOM}

The PAOM obtained is a pale-yellow powder and the molecular weight is less than 1000 . When AOM is added to an anion, two resonating forms, each of which is in equilibrium with its tautomeric anion as shown in Figure 9, give rise to four possible structures for the resonating chain unit. 1, 2-addition, 1, 4-addition and two hydrogen transfers. $^{2}$ In the case of the hydrogen transfer, the proton of the hydroxyl group can migrate on the carbon or nitrogen atom. Table II indicates data on the chemical analysis of PAOM. The

\begin{tabular}{|c|c|c|c|c|c|c|c|c|}
\hline \multicolumn{5}{|c|}{ Polymerization conditions } & \multirow[b]{2}{*}{$\begin{array}{c}\text { Yield, } \\
\%\end{array}$} & \multirow[b]{2}{*}{$\bar{M}_{n}$} & \multirow{2}{*}{$\begin{array}{c}\mathrm{C}=\mathrm{C} \\
\text { bond } \\
\%^{\mathrm{b}}\end{array}$} & \multirow{2}{*}{$\begin{array}{c}\text { Oxime } \\
\text { group }^{\mathrm{c}} \\
\%\end{array}$} \\
\hline $\begin{array}{l}{\left[\mathrm{M}_{0}\right]} \\
\mathrm{mol} / \mathrm{l}\end{array}$ & $\begin{array}{c}{[\mathrm{BuLi}],} \\
\mathrm{mol} / l\end{array}$ & Solvent & $\underset{{ }^{\circ} \mathrm{C}}{\text { Temp, }}$ & $\begin{array}{c}\text { Time, } \\
\mathrm{hr}\end{array}$ & & & & \\
\hline 13.74 & 0.045 & None & 30 & 6 & 13.8 & 820 & 50.7 & 42.8 \\
\hline Hydrolysis $^{\mathrm{a}}$ & & & & & & 450 & & \\
\hline 6.86 & 0.045 & DCE & 30 & 6 & 20.0 & 660 & 48.4 & 44.8 \\
\hline 6.86 & 0.045 & THF & 30 & 6 & 11.3 & 590 & 46.7 & 44.7 \\
\hline 13.74 & None & None & 60 & 3 & 21.7 & 2100 & 42.0 & 46.0 \\
\hline
\end{tabular}
ratio of structural units in PAOM seems to be independent of whether solvent is used or not, or the kind of solvent used. The lower molecular weight of PAOM produced by the BuLi catalyst, compared with that obtained thermally, ${ }^{2}$ will

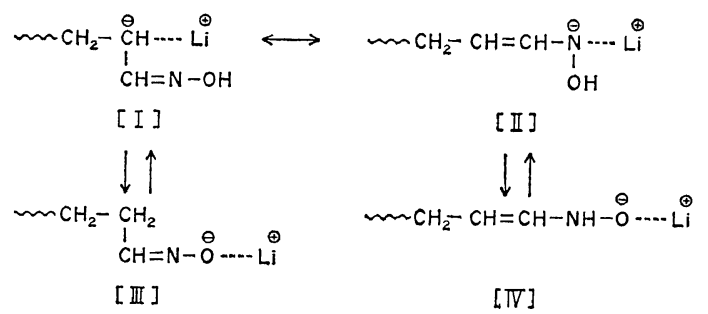

Figure 9. Resonance and equilibria for growing chain end.

Table II. Characteristics of PAOM

a PAOM obtained by bulk polymerization was hydrolyzed. Hydrolyzed PAOM: C, $44.60 \% ; \mathrm{H}, 7.43 \%$; $\mathrm{N}, 16.41 \%$.

b $\%$ of structural units having a carbon-carbon double bonds per unit.

c $\%$ of structural units having a pendant oxime group per unit. 
result apparently in a slight increase in the carboncarbon double-bond content because a terminal unit contains double bond. However no other significant differences can be detected.

From the data shown in Table 2, the distribution of the structural units for PAOM $\left(\bar{P}_{n}=12\right)$ obtained by the bulk polymerization is determined according to the treatment described previously ${ }^{2}$ as

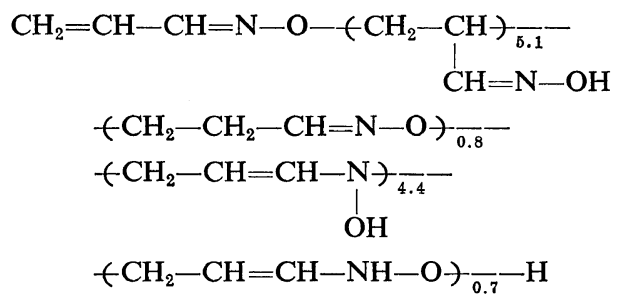

The NMR and IR spectra and the results of elemental analysis of hydrolyzed PAOM are shown in Figures 8 and 10 and Table II, respectively. The absorption peak at $900-1000 \mathrm{~cm}^{-1}$ is due to the $\mathrm{C}=\mathrm{C}$ and $\mathrm{N}-\mathrm{O}-\mathrm{C}$ linkages in the IR spectrum of PAOM, and signals at 7.71, 7.04, 6.40 and $5.50 \mathrm{ppm}$ are assigned to protons of the end group, $\mathrm{CH}_{2} \mathrm{CH}-\mathrm{CH}=\mathrm{N}-$, in NMR spectrum. ${ }^{3}$ As described previously, ${ }^{3}$ the syn form of AOM has peaks at 7.71, 6.40 and $5.50 \mathrm{ppm}$ and the anti form at 7.40 and $5.50 \mathrm{ppm}$. Broad peaks at 7.24 and $6.76 \mathrm{ppm}$ are assigned to the oxime side chain, $-\mathrm{CH}=\mathrm{N}-\mathrm{OH}$, of the syn and anti forms, respectively. Further, the spectrum indicates the signals at $4.92,4.50,2.00-4.00$ and $1.70 \mathrm{ppm}$ which are due to the linkages of $-\mathrm{O}-\mathrm{CH}_{2}-\mathrm{C}=$, $-\mathrm{O}-\mathrm{CH}_{2}-\mathrm{C}-$ and $-\mathrm{N}-\mathrm{CH}_{2}-\mathrm{C}-$, and the methylene protons in the polymer backbone, respectively. These assignments are consistent with the structure of PAOM described above.

On hydrolysis with sulfuric acid, the absorption at $900-1000 \mathrm{~cm}^{-1}$ diminishes in the IR spectrum, and the peaks at 7.71, 7.04, 6.40, and $5.50 \mathrm{ppm}$ disappear in the NMR spectrum. These findings indicate that $\mathrm{CH}_{2}=\mathrm{CH}-\mathrm{CH}=\mathrm{N}-\mathrm{O}-$ $\mathrm{CH}_{2}$ - linkage located to the chain ending, and $=\mathrm{N}-\mathrm{O}-\mathrm{C}$ and $-\mathrm{NH}-\mathrm{O}-\mathrm{C}$ linkages in the main chain, both resulting from hydrogen-transfer polymerization, clove on hydrolysis with sulfuric acid. The lowering of the molecular weight to one half its initial value by hydrolysis is in agreement with the fact that PAOM contains a hydrogen-transfer structural unit of 1.5 per a polymer. The presence of an aldehyde group in the hydrolyzed PAOM was revealed qualitatively by Fehling's test. However, it can be seen from the results of elemental analysis that a pendant oxime group in PAOM is slightly hydrolyzed. The IR spectrum of the hydrolyzed PAOM has a peak at $1600 \mathrm{~cm}^{-1}$ assigned to aldehyde group, which is broad due to the overlapping with the peaks assigned to the $\mathrm{C}=\mathrm{C}$ and $\mathrm{C}=\mathrm{N}$ vibrations. The red shift of absorption peak due to aldehydic carbonyl group seems to result from the formation of hydrogen bonding with a hydroxyl group. The hydrolyzed PAOM is soluble in water, since it

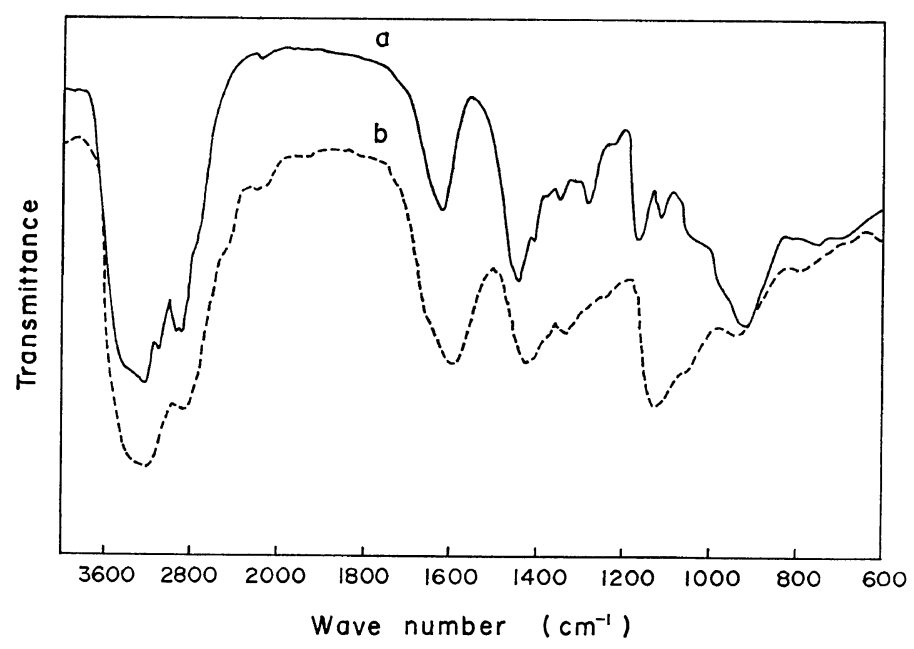

Figure 10. IR spectra: $a$, PAOM; b, hydrolyzed PAOM. 
AOM Polymerization by Butyllithium

contains a considerable amount of hydroxyl group and its molecular weight is low.

\section{REFERENCES}

1. S. Masuda and T. Ota, Polym. J., 9, 465 (1977).

2. S. Masuda, and T. Ota, Polym. J., 9, 459 (1977).

3. S. Masuda, H. Kihara and T. Ota, Nippon Kagaku Kaishi (J. Chem. Soc. Jpn.), 608 (1974).
4. Y. Toi and Y. Hachihama, Kogyo Kagaku Zasshi (J. Chem. Soc. Jpn., Ind. Chem. Sect.), 64, 595 (1961).

5. D. D. Van Slyke, Ber., 43, 3170 (1910).

6. I. P. Losev and O. Ya Fedotova, "Praktikum po Khimii Vysokopolymernykh Soedinii," Gosudarstvennoe Nauchno-Tekhnicheskoe Iodatelistvo Khimicheskoi Literatur, Japanese translation, Gihōdō, Tōkyo, 1965, p 67. 